\title{
Automated section for milling soil in near-trunk zones of orchard
}

\author{
Dmitriy Khort ${ }^{1}$, Rostislav Filippov ${ }^{1, *}$, Igor Smirnov ${ }^{1}$, Alexey Kutyrev ${ }^{1}$ and Stepan Semichev ${ }^{1}$ \\ ${ }^{1}$ Federal Scientific Agroengineering Center VIM, 1-st Institutsky proezd, 5, Moscow, 109428, Russia
}

\begin{abstract}
Machines used in gardens do not fully comply with the quality indicators of tillage, especially in the near-trunk zones of fruit trees. Theoretical analysis made it possible to establish that the preferred protective distance in the aisle of the garden should be at least $0.20 \mathrm{~m}$ in each direction, and in the interbarrel space of the boles along a row of $0.38 \mathrm{~m}$ and to establish the optimal width of the extension section of $0.55 \mathrm{~m}$. As a result of the research, an original design of the deflectable milling section of the garden milling cutter with an autonomous hydraulic system was proposed and developed, as working bodies knives with special sharpening are used. The tracking system of the remote section is equipped with a double remote probe, when exposed to which the section is retracted to the required distance to protect the trunk of a tree. The use of a deflectable milling section of a garden milling cutter allows to increase the accuracy and quality indicators of processing in the near-trunk zones of garden plantings, while the density of the soil decreases on average by $24 \%$.
\end{abstract}

\section{Introduction}

In the near-stem areas of fruit trees of intensive gardens, up to $90 \%$ of the entire root system is located. Weeds and poor-quality technological processing of the soil, negatively affect the crop shortage, reducing it by 20 $25 \%$. The near-stem zones are the most difficult to process and require the use of specialized machines, especially in intensive plantings $[1,2,3]$. Technological requirements for soil content in row spacing, perennial fruit stands require solving the issue of high-quality soil cultivation in near-trunk zones. Soil treatment with herbicidal preparations partially solves this problem; however, their use is not always possible due to high environmental requirements and is often not economically justified. The proposed assortment of chemical means of weed control does not fully meet the stringent requirements for the maintenance of near trunk zones and inter-trunk strips of orchards. To solve this problem, a deflectable milling section of a universal garden milling cutter for processing trunks with a bypass of fruit tree trunks was developed, which performs soil cultivation in accordance with all modern requirements for this technological operation with high-quality crumbling of soil in the inter-tree stripes of garden plantings.

The soil treatment operation in the near-trunk areas of perennial plantations is carried out by machines, the working bodies of which, approaching the tree trunk, leave a protective zone. Specialized machines used in farms often do not fully meet the requirements for the quality of the technological process of tillage in the ranks of perennial plantations, which leads to the forced simplification of agricultural technologies and to an under-harvest of fruit crops.
The purpose of the work is to justify the design parameters, develop a prototype and conduct preliminary tests of a garden milling cutter with a remote milling section in a production environment.

To solve this problem, a deflectable milling section of a universal garden milling cutter, which performs tillage in accordance with all modern requirements for this technological operation with high-quality crushing of the soil in interstitial plantations of orchards. The operation of tillage in the near trunk zones of fruit trees of perennial plantings is performed by machines, the working bodies of which, approaching the trunk of the tree, leave a protective zone. Specialized machines used in farms often do not fully meet the requirements for the quality of the technological process of tillage in the rows of perennial plantings, which leads to a forced simplification of agricultural technologies and to a shortage of fruit crops. The purpose of the work is to substantiate the design parameters, develop a mock-up sample and carry out preliminary tests of a garden cutter with an external milling section under production conditions.

\section{Materials and methods}

Theoretical studies were carried out using the provisions of mathematical analysis, analytical geometry and theoretical mechanics, taking into account the agrotechnical, technological, design and quality requirements for tillage in the inter-trunk zones of fruit plantations.

A special program and methodology for laboratory experimental research and preliminary testing was developed on the basis of the Russian industry standards,

\footnotetext{
* Corresponding author: rostislav-filippov@yandex.ru
} 
STO AIST 4.4-2010, GOST R 54784 - 2011, GOST R $52777-2007$ and other state and industry standards for testing agricultural machinery $[4,5,6,7]$.

Moisture and soil density indices were determined in a soil layer of $0 \ldots 15 \mathrm{~cm}$. Soil moisture was measured by drying samples at $105^{\circ} \mathrm{C}$., It ranged from $18.8 \%$ to $9.3 \%$. Soil density was measured by IP 271 electromechanical soil hardness tester, on average, its value amounted to $1.42 \mathrm{~g} / \mathrm{cm}^{3}$. The quality of soil cultivation was evaluated by the uniformity of the depth of cultivation, crumbling and cutting of weeds. The depth of soil cultivation was determined using a dipstick with an accuracy of $\pm 1 \mathrm{~cm}$. Crushed soil by fractions was evaluated using a set of interchangeable sieves based on the percentage of soil aggregates ranging in size from 1 to $50 \mathrm{~mm}$ or more. For this, control samples were taken in four places $1 \mathrm{~h}$ after the passage of the machine. The size of the sampling site for sampling is $0.25 \mathrm{~m}^{2}$ per processing depth. The percentage fraction of weeds destroyed was determined by the difference in the number of weeds before and after the passage of the machine.

From energy performance indicators, the ratio of fuel consumption per unit area to power fuel consumption $(\mathrm{kg} / \mathrm{ha})$ during operation and power consumed by the remote section $(\mathrm{kW})$ were determined. The energy intensity of soil cultivation by the external milling section was estimated using tensometric equipment consisting of an AKIP-4115 oscilloscope, and a rotary dynamometer, and the shaft rotation frequency was measured by VK-317 pulse sensors. The equipment was located in the tractor cabin, the power was supplied from the battery using a voltage converter for 1000 watts. Determination of the traction resistance of the deflected cutter section was not included in the test program.

Laboratory and experimental studies and preliminary tests were carried out on the experimental fields of the Federal Scientific Agroengineering Center VIM, in areas with fruit plantations, 3-5 years old and a planting scheme of $5 \times 3.5$ in the village of Maydanovo, Moscow region, from 12.05.18. on 10.09.18. The relief is flat, the microrelief is small-combed. Soils are sod-podzolic. The weed infestation was $90-170 \mathrm{pcs} / \mathrm{m}^{2}$.

\section{Results and discussions}

In the process of soil cultivation, between the rows of fruit orchards there is an untreated plow zone with a width of 30-60 cm, which is due to the special working conditions of the tillage machine in orchards, where the movement of the tractor in the immediate vicinity in a row of trees is impossible because of their crown. Therefore, machines for processing near-trunk zones are asymmetric with respect to the center of the row and have a lateral displacement mechanism for introducing working bodies into the row line and tracing tree trunks to a number of fruit stands $[8,9]$.

With lateral displacement, a complex movement occurs in which the remote section moves along an arc of a circle (Fig. 1).
If the tractor unit moves at a speed of $\mathrm{V}_{\mathrm{ag}}$ and the deviation rate of the outrigger section is $\mathrm{V}_{\mathrm{a}}$, point $\mathrm{O}$ moves along a certain path with a discrete speed of $V_{p}$, which constantly changes in magnitude and direction (Fig. 1).

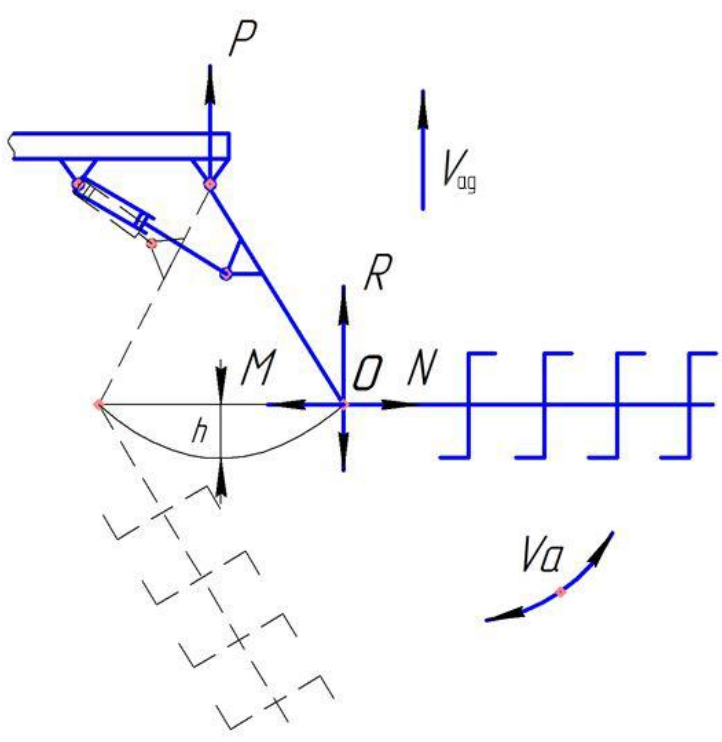

Fig. 1. Diagram of the deviation of the external milling section.

Point $\mathrm{O}$ moves along the $\mathrm{OO}_{4}$ curve with a break point $\left(\mathrm{O}_{2}\right)$, while these curve trajectories have a bend in the direction opposite to the movement of the unit. The change in the direction of the trajectory increases in the area $\mathrm{OO}_{1}$ and $\mathrm{O}_{2} \mathrm{O}_{3}$, since in the area $\mathrm{OV}$ the projection of the velocity $\mathrm{V}_{\mathrm{a}}$ on the $\mathrm{Y}$ axis is directed in the direction opposite to the movement of the machine. Similarly, we find the trajectory in the $\mathrm{O}_{2} \mathrm{O}_{3}$ segment as the point $\mathrm{O}$ moves from right to left. In areas $\mathrm{O}_{1} \mathrm{O}_{2}$ and $\mathrm{O}_{3} \mathrm{O}_{4}$, the trajectory of movement is obtained by adding the speed of movement of the unit and the projection of the speed of deflection of the extension section to the $\mathrm{Y}$ axis, since the speed $V_{\text {ay }}$ is directed along the direction of the unit.

The deflected section in the horizontal plane is acted upon: the thrust force $\mathrm{P}$, the reaction force of the soil, the resistance force $F$. In the process of withdrawing the milling section from the row axis, the following takeaway force of the hydraulic cylinder $\mathrm{M}$ and the reactive axial lateral cutting force $\mathrm{N}$ act (Fig. 2).

In our case, the movement of the milling section to be deflected occurs around a circle of radius $r$, therefore, the centrifugal force directed against the stroke of the unit is more pronounced.

When the tree trunk is framed by a milling working body under the action of the thrust force $\mathrm{P}$ and the force of withdrawal of the section by the hydraulic cylinder M, the point of the milling section $\mathrm{O}$ moves along a trajectory in the form of a parallelogram. Since the point in question is rigidly connected with the axis of rotation and moves along an arc of a circle while simultaneously moving progressively, a centrifugal force arises that counteracts the force of traction $\mathrm{P}$ and is characterized 
by an increased traction resistance transmitted to the whole unit.

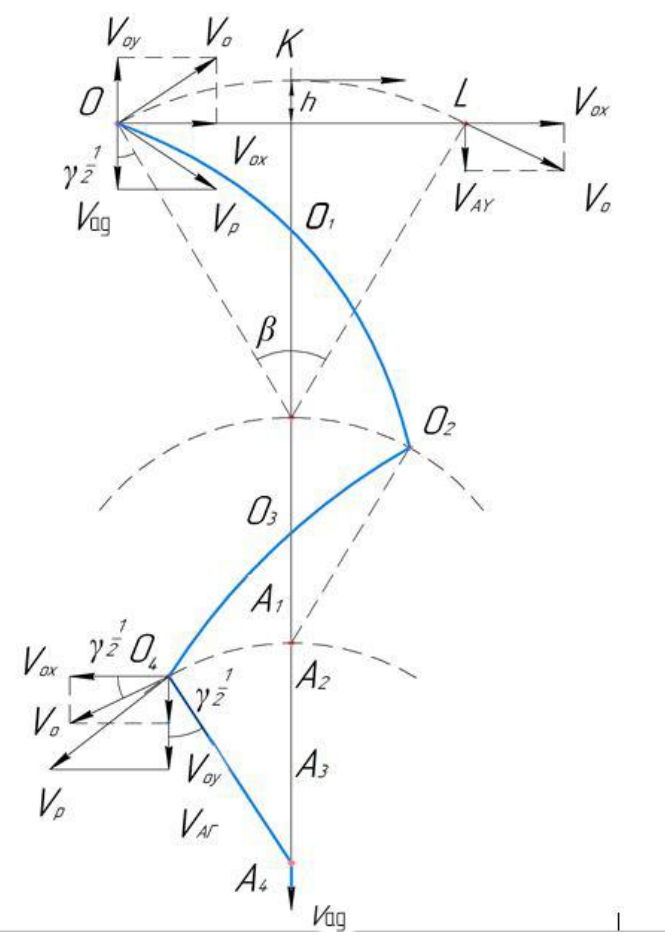

Fig. 2. Diagram of the deviation of the external milling section.

As a result of going around the tree trunk, the milling section moves along the trajectory (Fig. 3), making a complex movement:

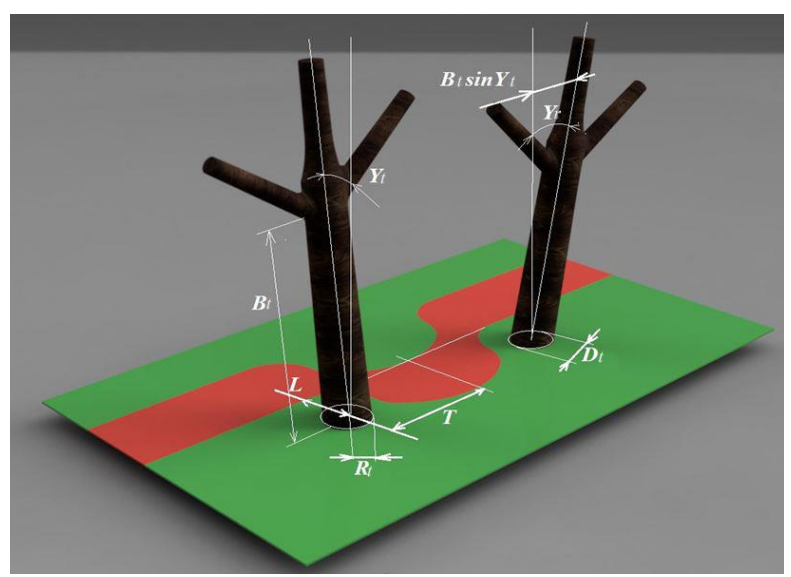

Fig. 3. Scheme to the definition of the protective zone of garden plants.

The relative movement of the remote section, we obtain from the equation

$$
x=L(1-\cos \omega t)
$$

The translational movement of the remote section, characterized by the equation

$$
\left.\left.y=T_{(} \omega t / \pi\right)=T_{(} \varphi / \pi\right)
$$

The value of the protective distance from the central axis of the tree trunk to the extreme points of the milling section perpendicular to the line of a number of plantings depends on the angle of inclination of the stem towards the row spacing, according to the formula:

$$
L=B_{t} \sin Y_{t}+R_{t}
$$

$H_{t}$ - height of fruit tree stump, m; $\sin Y_{t}$ - the angle of inclination of the tree trunk, deg; $R_{t}$ - radius of the fruit tree stump, $\mathrm{m}$

The values of the protective distance from the central axis of the tree trunk to the edge of the milling knives moving along the line of a number of garden trees, mainly depends on the diameter of the trunk (stem) of the tree at the widest point and to a lesser extent on the height of the stem and its angle of inclination along the line of a number of trees, is determined according to the formula

$$
T=D_{t}+2 H_{t} \sin Y_{t}
$$

From this it follows that to ensure the smooth operation of the machine and to prevent damage to the trunks and the root system of fruit stands, the protective zone during operation of the deflecting milling section should have the following parameters: orthogonal to the row (from the extreme point of the working body to the row line) $\mathrm{L}=19.32 \mathrm{~cm}$; along the line of the row $\mathrm{T}=$ $38.43 \mathrm{~cm}$. To ensure a protective zone during operation of the external milling section, its working width should not exceed $55 \mathrm{~cm}$.

As a result of the studies, the dimensional characteristics of the design of the deflected milling section with the drive of the working bodies from an independent hydraulic system were justified [10].

The deflectable milling section (Fig. 4) consists of a housing 1 , a hydraulic motor for the drive of the shaft of the knife drum 4, rigidly fixed working bodies in the form of knives, a hydraulic distributor of the section deflection system, a pressure drum and hydraulic cylinders for changing the position of the section in vertical and horizontal planes. The steel casing of the deflected section has protective shields to prevent the spread of small soil particles. The working shaft has a set of discs with a set of rigidly attached tillage knives

To exclude damage to the bark of trees during the detour of the boles, the section is equipped with an automatic deflection system, which consists of a dual probe 9 connected to a hydraulic distributor 3, which acts on the hydraulic cylinder 5 and the milling deviation from the longitudinal axis of the row in the inter-trunk space of the fruit garden occurs.

The results of studies and tests showed that, with an average speed of the unit moving $3.5 \mathrm{~km} / \mathrm{h}$, the depth of tillage averaged $8.7 \mathrm{~cm}$. The standard deviation was 1.24 $\mathrm{cm}$, the coefficient of variation was $13.9 \%$. When the external section was in operation, the size of the protective prishtamby zones of the trees did not exceed the calculated values, while the raw area around the boles was $0.28 \mathrm{~m}^{2}$. The destruction of weeds in the area of passage of the section was $98 \%$. 


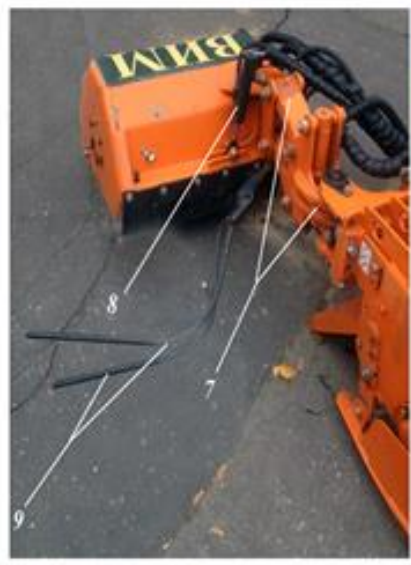

a

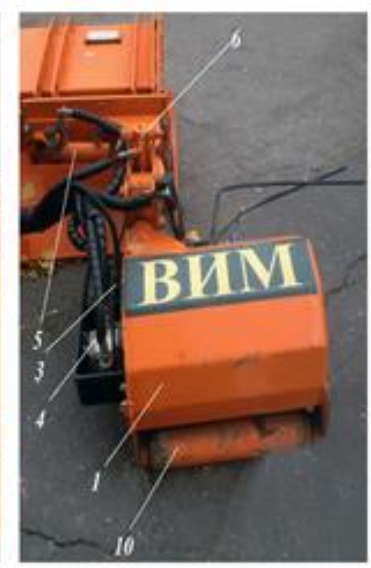

b
Fig. 4. Rejected milling section: a - front view, b - rear view. 1 - section casing; 2 - high pressure hydraulic hoses; 3 hydraulic valve of the remote section with the function of adjusting the sensitivity of the probe; 4 - hydraulic motor to drive the knife drum; 5 - hydraulic cylinder of the section rotation relative to the longitudinal axis of the row; 6 hydraulic cylinder lifting section; 7 - hinged section mounting; 8 - hydraulic cylinder for adjusting the section inclination in the vertical plane; 9 - double tracking probe system deviations from the boom section.

The crumbling of the soil into fractions after treatment was distributed as follows $[11,12]$ :

- the amount of coarse fraction more than $50 \mathrm{~mm}$ was $12.4 \%$;

- an average of $25-50 \mathrm{~mm}$ was $13.6 \%$;

- shallow 10-25 mm was $46.8 \%$;

- shallow 4-10 mm was $17.3 \%$;

- small 1.5-4 mm was $8.7 \%$;

- the content of erosion hazardous particles did not exceed $1.2 \%$.

As a result of the energy evaluation of the work of the remote section, a graph was obtained depending on the power spent on tillage during the removal of the remote section from the row axis (Fig. 5) [13]. The resulting graph showed that when bypassing the shtamba of the fruit tree, the energy consumption for driving the working bodies is reduced by $28 \%$. This is due to the change in the angle of operation of the knife drum due to a decrease in the width of the extension section. The specific fuel consumption was $15.22 \mathrm{~kg} / \mathrm{ha}$. Productivity per hour of basic time, $0.88 \mathrm{ha} / \mathrm{h}$, for comparison, the productivity of the serial mill FA-0.76 $-0.259 \mathrm{ha} / \mathrm{h}$.

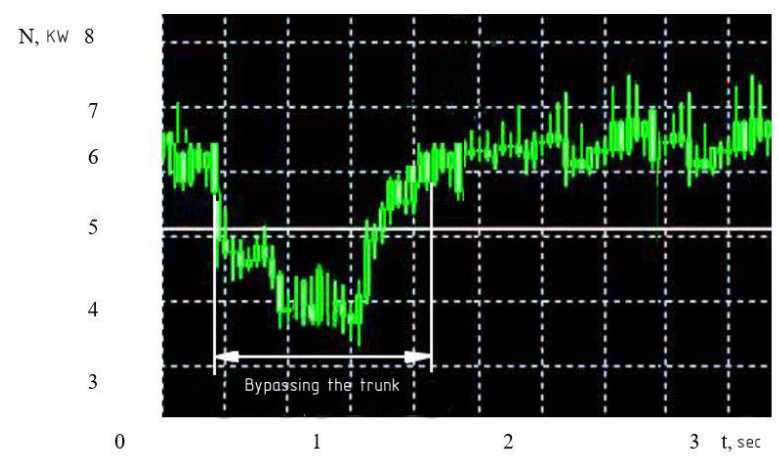

Fig. 5. Dependence of the power N, spent on the operation of soil milling, from time t.

The measurement results showed [14,15] that the soil density in the treated area varied from 1.05 to 1.09 with an average value of $1.07 \mathrm{~g} / \mathrm{cm}^{3}$, and in untreated areas from 1.37 to 1.48 with an average value of 1.42 g/cm ${ }^{3}$ (Fig. 6).

In figure 7 shows the process of operation of the cutter with a remote milling section.

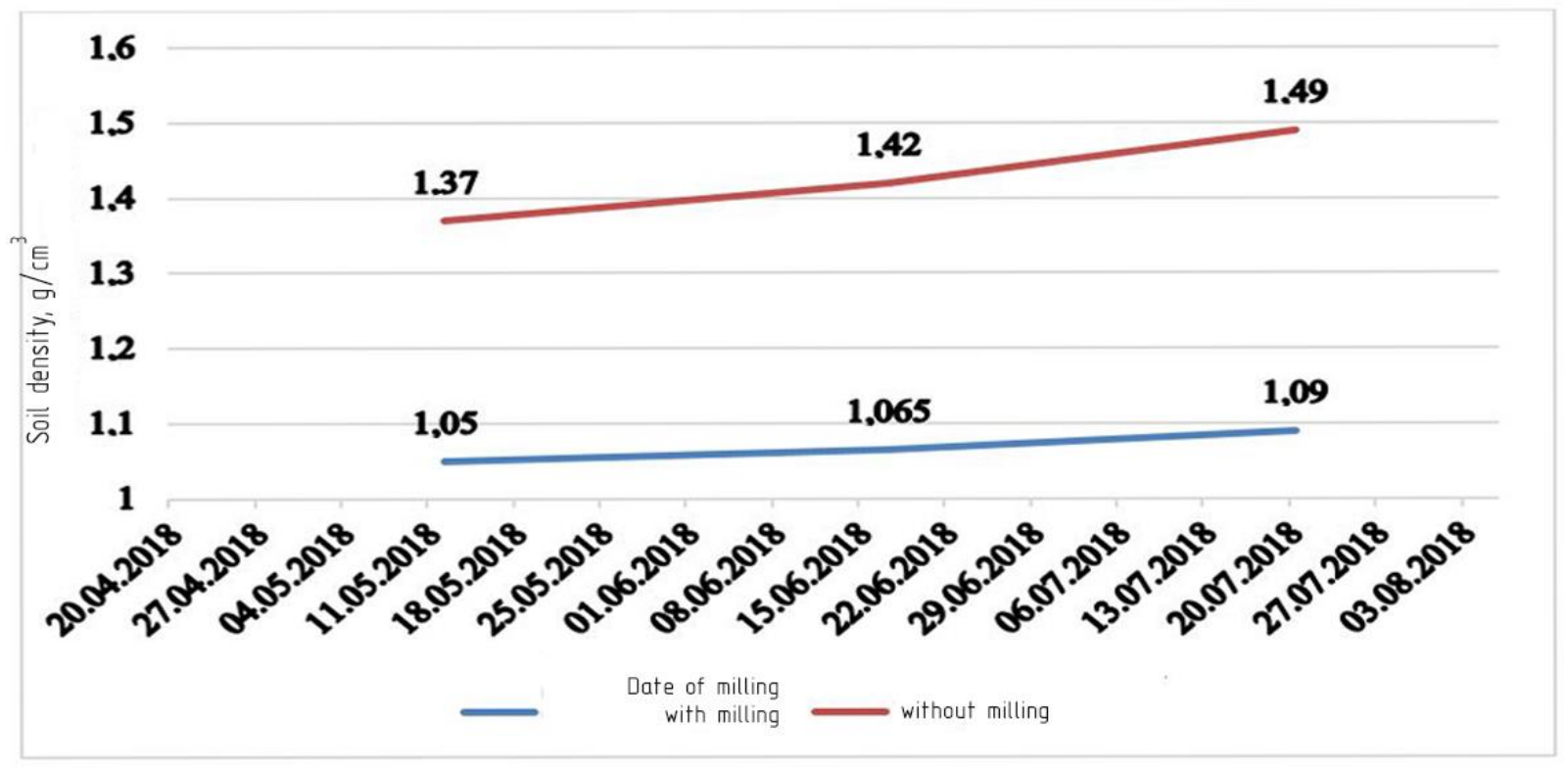

Fig. 6. Graph of changes in soil den. 


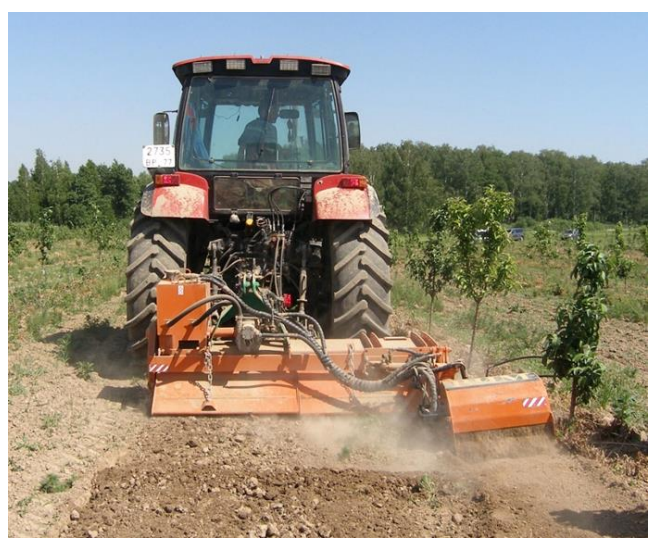

Fig. 7. Model of a garden cutter with a remote milling section in operation.

\section{Conclusions}

Tillage machines used in horticultural farms do not meet the required indicators for the quality of the technological process of tillage in the ranks of perennial plantations, this leads to a decrease in the yield of fruit and berry crops and an increase in the spread of weeds.

The theoretical analysis helped to justify the optimal size of the protective zones, which across the row should be at least $0.20 \mathrm{~m}$ in each direction, and for the boles along the row line of $0.38 \mathrm{~m}$, therefore, to provide these protective zones, the width of the deflected section should not be more than $55 \mathrm{~cm}$.

When processing the soil with a milling cultivator, the density of the soil in near-stem circles decreases on average by $24 \%$, and the energy consumption of milling in the process of bypassing the tree trunk decreases by $28 \%$.

The work of the remote section in field experimental studies helped substantiate the results of theoretical conclusions. In fact, the test results obtained, the area of the protective zone, the grinding of weed roots and the fractional composition of the soil fully comply with the technological requirements for the soil cultivation operation in the inter-span space of perennial plantations, and the practical use of a garden milling cutter with an additional remote section (milling) increases productivity by 1.5 times in comparison with the serial milling cutter FA-0.76, due to the larger working width of two sections, as well as to a higher working speed due to the speed of the guide outboard system.

\section{References}

[1] I.G. Smirnov, D.O. Hort, R.A. Filippov, Normative-technical database of machines for modern technologies of industrial gardening, Collection reports of the International ScientificTechnical Conference "System technologies and machines for the innovative development of the agricultural sector of Russia", 1, 202-205 (2013).

[2] I.G. Smirnov, D.O. Hort, R.A. Filippov, N.N. Romanyuk, S.V. Esipov, Improving the processing technology of the inter-stem zone between the rows of horticultural plantations in the external milling section, Bulletin of the Ryazan State Agrotechnological University named after P.A. Kostycheva, 4, 34, 83-88 (2018).

[3] S. Ozpinar, A. Ozpinar, A. Cay, Soil management effect on soil properties in traditional and mechanized vineyards under a semiarid Mediterranean environment, Soil and Tillage Research, 178, 198-208 (2018).

[4] B.A. Armor, Field experience, M.: Alliance, 351 (2014).

[5] GOST R 54784-2011, Tests of agricultural machinery. Methods for assessing technical parameters, Moscow: Standarinform, 19 (2012).

[6] STO AIST 4.4-2010, Machines and tools for tillage in gardens, vineyards, hop in the mildew and berries. Methods for assessing functional indicators, Moscow: Rosinformagrotech, 37 (2013).

[7] GOST R 52777-2007, Agricultural machinery. Energy assessment methods, Moscow: Standarinform, 6 (2008).

[8] R.A. Filippov, Improving the efficiency of using high-profile milling cultivator in horticulture, Collection of reports of the International Scientific and Technical Conference "Intelligent machine technology and equipment for the implementation of the state program of agricultural development", 1, 336-339 (2015).

[9] Md.A. Matin, J.M. Fielke, M.A. Jacky, Furrow parameters in rotary strip-tillage: Effect of blade geometry and rotary speed, Biosystems Engineering, 118, 7-15 (2014).

[10] R.A. Filippov, D.O. Hort, Garden universal milling cutter FSU-2.5, Collection of reports of the International Scientific and Practical Conference "Young Scientists in Solving Actual Problems of Science", $42-43$ (2014).

[11] M. Mairghany, Azmi Yahya, N.M. Adam, Ahmad S. Mat Su, Suha Elsoragaby Rotary tillage effects on some selected physical properties of fine textured soil in wetland rice cultivation in Malaysia, Soil and Tillage Research, 194 (2019).

[12] J.D. MacDonald, L.R. Costello, J.M. Lichter, D. Quickert, Fill soil effects on soil aeration and tree growth, J. Arboric., 30, 1, 19-27 (2004).

[13] R.M. Anpat, Raheman H. Investigations on power requirement of active-passive combination tillage implement, Engineering in Agriculture, Environment and Food, 10, 4-13 (2017).

[14] P. Catania, M. Vallone, F. Pipitone, G.F. Argento, G. Spartà, V.A. Laudicina, Soil management effect on soil penetration resistance in the vineyar, J. Agric. Eng., 44, 344-347 (2013).

[15] G. Coulouma, H. Boizard, G. Trotoux, P. Lagacherie, G. Richard, Effect of deep tillage for vineyard establishment on soil structure: a case study in southern France, Soil Tillage Res., 88, 132-143 (2006). 